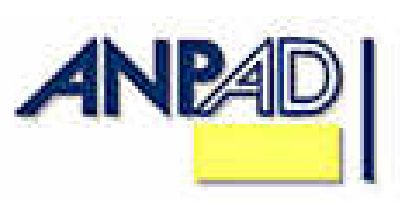

Disponível em

http://www.anpad.org.br/rac

RAC, Curitiba, v. 13, n. 1, art. 1, p. 1-16, Jan./Mar. 2009

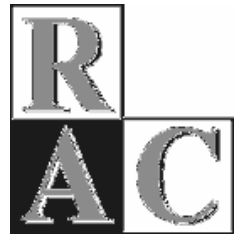

\title{
O Tema da Proteção Ambiental Incorporado nos Discursos da Responsabilidade Social Corporativa
}

\section{Environmental Protection Theme at Discourses of Corporative Social Responsibility}

\author{
Alexandre de Pádua Carrieri * \\ Doutor em Administração pela UFMG. \\ Professor do CEPEAD/FACE/UFMG, Belo Horizonte/MG, Brasil. \\ Alfredo Rodrigues Leite da Silva \\ Doutor em Administração pela UFMG. \\ Professor da FUCAPE Business School, Vitória/ES, Brasil. \\ Thiago Duarte Pimentel \\ Mestrando do CEPEAD/FACE/UFMG, Belo Horizonte/MG, Brasil.
}

* Endereço: Alexandre de Pádua Carrieri

CEPEAD / FACE / UFMG, Rua Curitiba, 832/1202, Centro, Belo Horizonte/MG, 30170-120. E-mail: alexandre@cepead.face.ufmg.br

Copyright @ 2009 RAC. Todos os direitos, inclusive de tradução, são reservados. É permitido citar parte de artigos sem autorização prévia desde que seja identificada a fonte. 


\section{RESUMO}

O objetivo do estudo é evidenciar e discutir a configuração dos discursos sobre a responsabilidade social nas organizações, assim como a sua incorporação da temática ambiental. Assume-se que várias estratégias são adotadas para disseminar determinado discurso sobre essas questões. Porém as ambigüidades inerentes à inserção desses temas nas organizações remetem a um discurso fragmentado (Fineman, 1996), revelando práticas de abertura e de dissimulação. A discussão teórica parte do tema responsabilidade social, o confronta com a temática ambiental e relaciona os discursos com as ambigüidades das práticas organizacionais oriundas dos dois temas. Por fim, um estudo de caso na Antena embasa a discussão. Os dados foram coletados por meio de pesquisa documental e de 40 entrevistas semi-estruturadas. Foi utilizado o método da Análise do Discurso (Fiorin, 1989). Como conclusão, comprovou-se que a preocupação com a responsabilidade social, já incorporando a temática ambiental, permeia a organização. Ela está na fala e em ações da alta direção, dos gerentes e de boa parte dos técnicos. Entretanto o silêncio sobre os limites dessa responsabilidade é preenchido por um grupo de técnicos que revela a dissimulação, quando a abertura ameaça seus objetivos específicos.

Palavras-chave: responsabilidade social; discursos; temática ambiental.

\section{ABSTRACT}

This paper views and discusses discourses on social responsibility in organizations and their use of the environmental theme. We suppose that strategies are used to disseminate some discourses concerning these matters. The ambiguities of themes within organizations point to a fragmented discourse (Fineman, 1996), revealing practices of openness and dissimulation. The theoretical discussion starts with the theme of social responsibility, confronting it with an environmental theme and discusses discourses with ambiguities of organizational practice stemming from two themes. At the end, a case study of Antena completes the discussion. Data was collected with documental research and semi-structured interviews. We made use of Discourse Analysis methodology (Fiorin, 1989). In conclusion, the concern with social responsibility and its environmental thematic lie within the organization. It is found in the discourse and actions at a high administration level including managers and a high number of technical workers. The silence about the limits of this responsibility is fulfilled by a technical workers group that reveals dissimulation when openness menaces some objectives.

Key words: social responsibility; discourses; environmental theme. 


\section{INTRODUÇÃO}

As preocupações com as questões sociais e ambientais ocupam lugar de destaque na contemporaneidade. Um olhar no cotidiano de muitas cidades brasileiras evidencia a ausência ou queda de qualidade de vida de parcela expressiva da população. Esse fenômeno remete a demandas e responsabilidades que envolvem toda a sociedade, o que inclui as organizações. Para essas últimas a disseminação do termo responsabilidade social tem marcado o peso de suas ações, com o potencial de agravar ou atenuar problemas sociais e ambientais de algumas comunidades. Por exemplo, a modernização de uma unidade produtiva pode ter como efeito a demissão de antigos funcionários, ou a troca de uma matéria-prima por outra com menor custo pode ampliar os níveis de poluição. Além disso, também se discute o uso de parte do lucro das organizações em ações voltadas para os interesses da sociedade.

As inúmeras possibilidades que envolvem as organizações exigem certa atenção dos interessados em discutir as questões sociais e ambientais. Esse entendimento remete à importância deste estudo, com o objetivo de evidenciar e discutir a configuração dos discursos sobre a responsabilidade social nas organizações e sua incorporação da temática ambiental. Aqui, o sentido de responsabilidade social se baseia em Carroll (1998), considerado um processo que deve envolver desde os acionistas, passando pelos funcionários, até a sociedade como um todo. Esse processo deve incorporar quatro faces inter-relacionadas em constante tensão: econômica, legal, ética e filantrópica. A partir desses aspectos a intenção de Carroll (1998) era expor uma direção para a boa cidadania corporativa. Entretanto, neste artigo, suas contribuições norteiam um olhar sobre como os caminhos estão sendo trilhados.

Para embasar essa discussão adotou-se a análise das estratégias discursivas de persuasão desenvolvidas nas organizações, pois permite evidenciar as relações de seus atores e de suas práticas vinculadas à responsabilidade social e à incorporação da temática ambiental. Isso será evidenciado pela discussão em bases teóricas e por meio de investigação empírica numa empresa do setor de telecomunicações: a Antena ${ }^{(1)}$. A escolha se justifica por ser um setor que tem passado por muitas modificações após a privatização em 1998, enfrentando concorrência, abertura de mercado e transformações tecnológicas com variadas implicações sociais e ambientais. A metodologia da investigação está baseada em elementos da Análise do Discurso [AD] (Fiorin, 1989); como, por exemplo, os percursos semânticos, a seleção lexical e a construção das personagens. A AD foi adotada por permitir vislumbrar a organização como espaço de embate de múltiplos discursos, na busca pela mudança e pelo controle (Reed, 1998).

Para desenvolver essa abordagem nos próximos três tópicos, o artigo discute o tema responsabilidade social, o confronta com a temática ambiental, e relaciona os discursos com as ambigüidades das práticas organizacionais referentes às duas questões. Em seguida, apresenta um estudo de caso, realizado na Antena, para confrontar as proposições teóricas com evidências empíricas. Por fim, são feitas as considerações finais do estudo.

\section{A RESPONSABILIDADE SOCIAL NAS ORGANIZAÇÕES}

Ashley, Coutinho e Tomei (2000) destacam que o conceito de responsabilidade social vem evoluindo quanto à capacidade de sua operacionalização e mensuração, subdividindo-se em diferentes vertentes de análise. Entre as vertentes estariam a responsabilidade social corporativa, o desempenho social corporativo, a atitude social corporativa, a auditoria social e inovação social. Os conceitos se diferenciam por enfatizarem alguns aspectos distintos; mas, como mostra Carroll (1998), é possível observar uma direção comum a eles: a intenção de oferecer referências para as práticas e o desempenho social das organizações. 
No tocante às práticas relacionadas com responsabilidade social, Melo (1999) destaca uma mudança no foco, passando pelas ações meramente filantrópicas até as ações mais substanciais que proporcionem desenvolvimento social. Para Schommer e Fischer (1999, p. 106), a discussão sobre essas questões realmente se intensificou no Brasil "especialmente a partir da criação do Instituto Ethos de Empresas e Responsabilidade Social, em Setembro de 1998". Entretanto, de certa maneira, os autores discordam de Melo (1999). Eles observam que, no cotidiano organizacional brasileiro, o entendimento de responsabilidade social se relaciona diretamente com as ações voltadas para o lucro. Pode até mesmo incluir ações filantrópicas ou outras com mais substanciais para a comunidade, desde que também haja retorno para a empresa. Nesse sentido, o conceito de responsabilidade social implicaria duas lógicas que convivem no espaço organizacional. Em uma estaria um modelo de gestão que apregoa a ênfase na abertura à responsabilidade e à ética; em outra surge a filantropia de alto rendimento, com foco no marketing, no endomarketing, nas exigências do mercado, e em restrições e benefícios legais oriundos do governo.

Martinelli (1997) ilustra esse argumento ao afirmar que há organizações atuando no campo de responsabilidade social, ao visualizarem oportunidade de negócios. Outras atuam como organização social, por se preocuparem em manter um relacionamento harmonioso e ético com todos que compõem seus grupos de interesse, sejam esses clientes, fornecedores, governos, acionistas ou sociedade. Existem também aquelas que atuam como empresas cidadãs, ao contribuírem para o desenvolvimento social e por assumir esse compromisso. Não cabe aqui um julgamento simplista, valorizando a abertura altruísta e desprezando os objetivos organizacionais específicos, como o retorno em termos de imagem. É esperado que as organizações busquem construir uma impressão positiva em seu público-alvo, e que para isso gerenciem uma imagem de responsabilidade social que incorpore a temática ambiental. O problema está na dissimulação fictícia. Nela, o objetivo de construir uma imagem positiva, algo legítimo, justificaria a farsa e a hipocrisia contra possíveis articulações sociais.

As pressões que levam as organizações a optarem por essa alternativa são semelhantes às que norteiam as ações concretas, a complexidade e politização da sociedade, ou seja, as corporações têm que sobreviver em ambientes complexos e politizados; portanto os gestores buscam o que é legítimo na percepção da sociedade (Alvesson, 1990). Isso se explica pelo fato de as organizações fazerem parte de um ambiente social do qual elas são dependentes (Reed, 1996). Conforme Hooghiemstra (2000), o modelo da legitimidade é amplamente usado para explicar os processos de divulgação e exposição de comportamentos em prol da temática social e ambiental nas organizações. Para o autor, como os limites e as normas sociais podem mudar, as organizações têm que demonstrar continuamente a legitimidade de suas ações. As organizações assumiriam, então, uma dimensão ética, social, e ambiental para mediar sua imagem e ganhar o respeito das comunidades com as quais interagem.

A síntese desses interesses no tocante à temática da responsabilidade social é oferecida por Carroll (1998), que os sintetiza nestas faces: econômica; legal; ética; e filantrópica. Elas são consideradas responsabilidades interdependentes, entre as quais existe contínua tensão nas organizações. Dessa maneira, tanto o público organizacional interno quanto a sociedade como um todo são considerados. A amplitude desse entendimento justificou sua adoção neste estudo, mas sem que se considere, a priori, a existência de todos esses aspectos nas organizações, muito pelo contrário. $O$ sentido de responsabilidade social aqui assumido é de que ela designa práticas que envolvem esses aspectos, mas não necessariamente todos.

Defende-se a idéia de que os atores organizacionais interpretam, reconhecem, dissimulam ou excluem esses fatores do seu entendimento de responsabilidade social, bem como julgam as práticas organizacionais como corretas, ou não, a partir dessas construções sociais. Portanto uma ou outra face pode não estar presente nessas práticas, tampouco no entendimento de determinado grupo de atores sociais, inserido numa organização específica. Como as organizações são compostas por diversos grupos, isto é, pessoas com histórias de vida, profissões, níveis sociais distintos, nem mesmo é possível afirmar que numa mesma organização haverá homogeneidade no discurso que revela essas construções em seu interior.

Os diferentes contextos em que esses atores se inserem tendem a ser fonte de ambigüidade. Podem 
ser citadas as pressões como a qualidade de vida da família que reside próxima à organização, e o aumento do desempenho do setor para atingir uma meta premiada, mas com prejuízo de normas de segurança ou ambientais. Aqui, surgem as tensões entre as faces da responsabilidade social, destacadas por Carroll (1998), resultado do entrecruzamento de questões legítimas na atualidade. Algumas, como a busca do lucro de uma organização privada, costumam ser excluídas do discurso; outras comumente são associadas à responsabilidade social, como as que Zouain (2001) destaca: a gestão do meio ambiente, a transparência nas ações, a preocupação com o público interno, com os fornecedores, com a comunidade, com o governo e a sociedade. Mas o fato é que no cotidiano de uma organização empresarial há muita convivência, dependência e confronto entre elas.

A primeira delas, a gestão do meio ambiente, é focada neste estudo, no sentido de se observar a maneira como a temática ambiental se insere ao lado de outras presentes na configuração do discurso da responsabilidade social.

\section{A temática ambiental, a Responsabilidade Social e as Pressões sobre as ORGANIZAÇÕES}

Para Shrivastava (1994), as organizações incorporam a responsabilidade social na medida em que surge uma consciência ecológica das pressões coletivas do uso da biosfera e da necessidade de manutenção dos recursos (materiais e humanos) necessários à produção. Os discursos relacionam a temática ambiental com a questão da responsabilidade social das organizações. Um exemplo é a associação Business for Social Responsibility, com membros que empregam milhões de trabalhadores. Sua finalidade é providenciar assistência para as ações, práticas e políticas que contribuam para sustentar e tornar responsáveis os negócios para os acionistas, empregados, consumidores, parceiros, comunidade e meio ambiente.

$\mathrm{Na}$ medida em que essas articulações se disseminam, a legitimidade de certificações, como a ISO $14000^{(2)}$, cresce. Bittencourt, Zimmer e Foelkel (1997) evidenciam a crença de que a ISO 14000 contribuiria para a construção de um mundo melhor, a partir da consciência e da responsabilidade que propõe desenvolver. Dessa forma, a sustentabilidade apareceria como necessidade de resposta do atual modelo de desenvolvimento aos gargalos ambientais e de atender às demandas por produtos e processos mais limpos.

Mas esse discurso não se configura de maneira homogênea na prática das organizações. Os contextos social, político e econômico influenciam diretamente as políticas ambientais de um país. Kitamura (1994) deixa isso claro, quando afirma que em países centrais o desenvolvimento sustentável é uma proposta voltada à melhoria da qualidade de vida e da proteção ambiental. Em países periféricos, sem condições básicas, como a segurança alimentar e empregos, a sustentabilidade envolve, além do bem-estar social, as soluções para problemas dos meios de produção. Nesse último caso, o embate entre os interesses econômicos e as demandas ambientais se intensificam. Entretanto deve-se destacar que as pressões sobre os interesses econômicos não se restringem ao país em que determinada organização se instala, pois não existe apenas um nível local de pressão social.

No Brasil isso pode ser observado na configuração multissetorial do movimento ambientalista, formado por (Viola, 1996): 1) ONGs e grupos comunitários nacionais e internacionais; 2) agências estatais; 3) grupos e instituições científicas de pesquisa; 4) administradores e gerentes voltados para a eficiência no uso dos materiais e da energia; 5) um mercado consumidor interessado em produtos que não prejudiquem a saúde nem o meio ambiente ${ }^{(3)}$; 6) redes multissetoriais que estabelecem e certificam o caráter sustentável de processos produtivos e logísticos; e 7) agências e tratados internacionais.

As pressões desse movimento nas organizações brasileiras foram evidenciadas em estudos diversos, como os de Nascimento (1997) e de Gutberlet (1996). Os autores observaram nas empresas uma visão de proteção ambiental inserida numa tendência mundial, o que pode conferir vantagem competitiva, 
pois é um dos instrumentos de regulação do mercado global. Ao detalhar essa tendência, Donaire (1994) classificou as ações das empresas em três níveis: controle ambiental nas saídas, tecnologias de depuração ou de final-do-tubo; integração do controle ambiental em práticas e processos industriais, matérias-primas, desenvolvimento de processos e produtos; e integração do controle ambiental na gestão administrativa, a conservação ambiental como objetivo perseguido pela empresa.

Como a legislação comumente impulsiona a introdução da empresa apenas até o primeiro nível, para os demais há necessidade de outras pressões. Aqui, surge a importância da crescente conscientização dos consumidores, advinda da globalização da informação, determinando o aumento da demanda por produtos feitos com tecnologias limpas, de modo sustentável e diferenciado (Bonin, 1993). Na medida em que as organizações observam o aumento dessas pressões, os investimentos a ela relacionados tendem a ser destacados em seu discurso de responsabilidade social. Isso remete a uma possível mudança nas estratégias organizacionais, que se pode concretizar apenas como mudanças num discurso a ser disseminado, ou incluir alterações com impactos efetivos na temática ambiental.

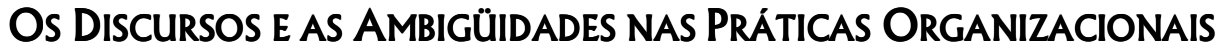

Carvalho (1991) contribui para o entendimento do que leva a certo alinhamento das organizações com a temática ambiental, ao destacar a inserção nessas organizações do que identificou como o discurso ecológico dito oficial, em oposição ao alternativo. O primeiro busca cooptar a discussão e legitimar o desenvolvimento industrial globalizado, tentando equacioná-lo com preservação ambiental e qualidade de vida. Ele é defendido por instituições governamentais nacionais e internacionais que apregoam a regulação das práticas ecológicas. O discurso alternativo se opõe ao primeiro por não ter compromissos com o desenvolvimento globalizado. O interesse das organizações em se alinharem com o primeiro é óbvio, reduzindo as pressões do segundo. Entretanto, mesmo ao se alinhar com o discurso dito oficial, surgem construções discursivas ambíguas, em torno de interesses diversos. Nelas, a busca por incorporar a temática ambiental à responsabilidade social inclui uma infinidade de novos elementos internos e externos às organizações, capazes de serem opostos aos seus objetivos específicos, como o lucro e a produtividade.

Em uma concepção normativa de responsabilidade social (Ashley et al., 2000), as organizações já conviviam com certa ambigüidade. Por exemplo, na análise da relação custo/benefício entre cumprir uma norma de segurança no trabalho e o cálculo dos valores e da probabilidade do pagamento de possíveis multas e indenizações. Neste caso, para ter responsabilidade social a organização deveria respeitar a norma e investir na segurança, convivendo com o fato de que essa alternativa envolve maior custo pelo menos num primeiro momento. $\mathrm{O}$ menor custo para muitos não deveria nem ser concebido como possibilidade; mas, na lógica da competitividade e do lucro, ele tende a aparecer numa planilha qualquer, gerando ambigüidades. Ao incorporar a temática ambiental, isso se expande, envolvendo desde a escolha da matéria-prima, passando pela necessidade de novos equipamentos e processos, até a opção por interromper linhas de produção, ou seja, novas questões passam a ser confrontadas com os objetivos organizacionais. Como consequiência, aumenta a possibilidade da fragmentação de discursos e práticas na organização.

Este estudo busca revelar como ocorrem essas configurações. Para isso optou-se por analisar os discursos na organização, veiculados por atores nos mais diversos níveis organizacionais, falando de suas práticas cotidianas. Nessa abordagem defende-se o discurso como o caminho capaz de evidenciar ações objetivas (um novo produto), subjetivas (a persuasão discursiva), bem como a interpretação de ambas por parte dos membros organizacionais. Nesse processo de interpretação, os atores lidam com as ambigüidades contextuais associadas aos interesses organizacionais e às suas próprias inserções na organização e na sociedade como um todo. Imersos nessas ambigüidades, eles as manifestam nos mesmos discursos que evidenciam seu cotidiano organizacional, marcado por ações efetivas e/ou dissimulações.

Quando a alta direção organizacional opta por um posicionamento em seus discursos, mas em suas 
estratégias defende outro, existe a possibilidade de muitos atores enfrentarem dificuldades para lidar com essa dualidade. Isso é algo que ocorre com certa frequiência nas organizações brasileiras. Maimon (1992) identificou três tipos de organizações no Brasil: a) as responsáveis, que agem conforme o seu discurso de proteção ambiental, geralmente numa gestão de longo prazo; b) as seguidoras, sem um discurso estruturado, elas seguem as normas dos órgãos de controle e as pressões ambientais; c) as mentirosas, que são contraditórias a respeito do seu discurso ambiental, atuam no curto prazo utilizando maquilagem para melhorar sua imagem.

O último grupo é marcado pela dissimulação, característica também observada por Fineman (1996), ao investigar a alta direção organizacional e identificar duas movimentações distintas: a) uma abertura à agenda verde; b) uma dissimulação em relação a ela. A dissimulação foi evidenciada como a mais recorrente, com a alta direção associando suas propostas a uma filosofia ambiental que não mude suas ações ou planos. Com essa base ela faz a devida propaganda, englobando discursos politicamente corretos. Essa constatação, aparentemente, indica a possibilidade de a organização obter vantagens sem os investimentos correspondentes. Entretanto é necessário destacar a dificuldade de lidar com os demais atores organizacionais, pois eles se inserem na ambigüidade, entre a dissimulação na direção de uma abertura e as práticas efetivas, defendidas no cotidiano. Isso explica a multiplicidade de formações discursivas coexistindo dentro das organizações.

Os discursos revelam essas configurações na medida em que são utilizados no cotidiano para a construção e manutenção das organizações (Weick, 1991). Concordando-se com Holmer-Nadesan (1996), parte-se do pressuposto de que os discursos não constituem somente significados para termos e práticas sociais, mas antes de tudo revelam as visões de mundo predominantes nas organizações. Isso mostra a importância de evidenciar e discutir as configurações discursivas sobre responsabilidade social e a incorporação da temática ambiental, ou seja, é um caminho para observar, de maneira aprofundada, essas temáticas e sua fragmentação no interior da organização. Para confrontar esse argumento com um rebatimento em evidências empíricas foi realizado um estudo de caso na Antena.

\section{Percurso Metodológico do Estudo de Caso}

Nesta investigação adotou-se a abordagem qualitativa; portanto a legitimidade das proposições inferidas não está, necessariamente, no número de casos ou respondentes, mas na maneira de lidar com o essencial na explicação de regularidades descobertas (Fernandes, 1973). Neste caso, essa maneira tem como base as contribuições teóricas sobre a responsabilidade social, a temática ambiental e a Análise do Discurso [AD]. Entre os anos de 2002 e 2004, tais contribuições embasaram uma pesquisa documental na empresa e no sindicato, assim como em entrevistas semi-estruturadas (Thiollent, 1987).

O grupo de sujeitos da pesquisa foi definido, quando se observou a saturação das informações referentes ao objeto em estudo (Poirier, Clapier-Valladon, \& Raubaut, 1983). A investigação se iniciou com 20 sujeitos, distribuídos entre a alta direção, a gerência, os técnicos e os membros do sindicato. A partir desse grupo, mais sujeitos foram inclú́dos, de acordo com o desvelar dos dados e a necessidade de argumentações adicionais, até a saturação dos dados ficar evidente na quadragésima entrevista.

Para a análise dos dados adotou-se a AD, dentro do entendimento de Fiorin (2003, p. 11), para quem "o discurso são as combinações de elementos lingüísticos (frases ou conjuntos constituídos de muitas frases), usadas pelos falantes com o propósito de exprimir seus pensamentos, de falar do mundo exterior ou de seu mundo interior, de agir sobre o mundo". O discurso se constitui da interação com outros discursos, nas dimensões interdiscursiva e intradiscursiva, organizadas por meio das contradições (Faria, 2001).

A categoria de análise do interdiscurso é a contradição, que permite caracterizar por oposição a um dado discurso um outro, com diferente visão de mundo. $O$ intradiscurso tem no percurso semântico e 
em seus subconjuntos a principal categoria descritiva que veicula a visão de mundo defendida e organizada, implícita ou explicitamente, por meio de temas e figuras. Os temas englobam elementos abstratos, como alegria e traição; já as figuras utilizam elementos do mundo natural, como mulher e casa (Faria, 2001; Fiorin, 2003). Tais elementos foram identificados ao se analisar, nos textos orais e escritos, as seguintes estratégias de persuasão discursiva: construção de personagens; seleção lexical; silenciamento; relação entre elementos explícitos e implícitos.

Deve-se destacar que as estratégias discursivas do locutor não garantem o controle, porquanto, ao serem interpretadas, podem revelar conteúdos indesejáveis pelo primeiro. Por isso, quando o pesquisador assume a condição de destinatário dos discursos dos sujeitos de pesquisa e dos documentos coletados, ele consegue lidar com as tentativas dos locutores de ocultar o que não interessa a eles. Algo possível, pois a análise das estratégias de persuasão descritas revelam regularidades que confirmam determinados discursos, ou a eles se contrapõem. Seguindo esse caminho, neste trabalho buscou-se evidenciar essas regularidades e retirar delas a articulação necessária, para se evidenciar e discutir a configuração dos discursos sobre responsabilidade social e a incorporação da temática ambiental na Antena.

\section{A EMPRESA EM ESTUDO: UM POUCO SOBRE A ANTENA}

Em 1993 se iniciou o negócio de telefonia móvel celular, um projeto da Antena ${ }^{(4)}$. Em 1998 ocorreu a cisão do serviço móvel celular e a constituição de empresas independentes. A Antena foi então privatizada. Conforme um de seus diretores, o início dessa trajetória foi marcado pela preocupação em atender os clientes o mais depressa possível, construindo antenas no espaço urbano sem muitos estudos.

Entre os anos de 2000 e 2001, as empresas do setor sofreram pressões de movimentos sociais referentes às torres de transmissão. Então, a Agência Nacional de Telecomunicações [Anatel], reguladora do sistema, baixou portaria recomendando para as torres e aparelhos de celular os índices europeus de emissão de radiação eletromagnética. Como resposta às pressões, a Antena apoiou um estudo sobre as emissões eletromagnéticas das antenas de telefonia celular ${ }^{(5)}$.

A união da Antena com a Amazônia Celular (em Belém) também surge como possível influência sobre suas relações com o meio ambiente. Segundo um diretor: "A Amazônia faz isto. Nós temos que ir e vir muito lá; então isto ajuda, ver a floresta, o verde, isto ajudou muito aqui. Pensar na construção das antenas, da reciclagem de bateria". Duas questões destacadas no site da empresa na Internet, em conjunto com seu 'Sistema de Gestão Ambiental' [SGA] e sua certificação ISO $14001^{(6)}$. Ao analisar o site da Antena, os documentos, e as entrevistas, observou-se a posição da empresa sobre essas questões ao apresentar explicações referentes aos seus cuidados para com o meio ambiente. Isso evidenciou o uso do discurso da responsabilidade social e da temática ambiental como caminho para legitimar e diferenciar a organização.

O discurso é direcionado a todo o estado de Minas Gerais, onde a empresa, em 2003, contava com mais de um milhão de clientes (73\% do mercado), 1.500 funcionários, 23 lojas próprias, 7 mil pontos de venda, atingindo cerca de 16 milhões de habitantes, em mais de 292 localidades. A disseminação desse discurso se dá por meio de diferentes estratégias discursivas e ações a serem discutidas a seguir.

\section{O PERCURSO SEMÂNTICO dA RESPONSABILIDADE SOCIAL}

Segundo os entrevistados, o tema responsabilidade social começou a se disseminar na organização após sua privatização, mas é considerado um aprofundamento das ações que a antiga Antena (a 
operadora fixa) fazia em relação à promoção de eventos culturais e esportistas na cidade de Belo Horizonte. O sentido de aprofundamento vem da fundação do Instituto Antena, por parte da empresa, no ano 2000, atribuindo a ele o objetivo de viabilizar que a organização contribua com as causas sociais. O Instituto é uma entidade para o fomento de projetos, iniciativas e programas destinados a servir às comunidades menos favorecidas de Minas Gerais. Segundo os funcionários do Instituto, sua principal ação é o acompanhamento da criação e do desenvolvimento de projetos da Antena. Nas reuniões desses projetos são levados em conta principalmente quais serão as parcerias, suas repercussões, seus gastos para a empresa. Apesar de que ele é mencionado como Instituto independente, no sentido da sua autonomia em face da direção da organização, pôde-se constatar que a Antena é a responsável pelo financiamento dos projetos e pagamentos dos funcionários. O Instituto deve prestar contas à Antena, desde seus gastos até seus projetos.

Dessa forma, a empresa promove seu nome e sua gestão por meio do Instituto. Ele entra como gestor desses encontros, mais especificamente dos projetos que já foram iniciados por outras instituições e órgãos públicos. Um exemplo é o Projeto Pró-Fia, ele é apenas um dos gestores para a expansão do Fundo dos Direitos da Infância e da Adolescência [FIA], autorizado pela Lei Federal 8.242/91. O Instituto criou o PRÓ-FIA como forma de gerir esse programa Federal. Por meio dele consegue ampliar a imagem da Antena. As ações sociais do Instituto abrangem os 853 municípios de Minas Gerais, incluindo o Triângulo Mineiro, fora da área de atuação da empresa. Seu principal programa é o Pró-Conselho, conjunto de projetos que visa fortalecer o Sistema de Garantia dos Direitos da Criança e do Adolescente, estimulando o cumprimento das determinações do Estatuto da Criança e do Adolescente [ECA]. Esse programa tem como principais parceiros a UNICEF, o Conselho Estadual dos Direitos da Criança e do Adolescente, e o Ministério Público de Minas Gerais. O Instituto foi citado de maneira recorrente pelos entrevistados, sejam eles técnicos ou gerentes.

Quando mencionada a responsabilidade social, os respondentes direcionaram seus argumentos para a sociedade, sem apresentar demandas (segurança, renda, qualidade de vida, etc.) do seu grupo social, diretamente submetido à organização, ou seja, a responsabilidade social é vista como algo direcionado ao público externo. Nesse sentido, as argumentações sobre o tema giraram em torno da relação entre responsabilidade, marketing, questões sociais e ambientais sempre ligadas à sociedade.

\section{O Percurso Semântico da Responsabilidade Social para os Gerentes}

Segundo o depoimento de um gerente, as ações em relação à responsabilidade social de todas as empresas poderiam ser divididas em quatro níveis: no primeiro não existe responsabilidade social; no segundo nível responsabilidade social é sinônimo de marketing; no terceiro nível a responsabilidade social é algo isolado; no quarto nível a responsabilidade social é associada à responsabilidade ambiental. Para o gerente, esses níveis são considerados evolutivos, indo da inexistência de responsabilidade social até a responsabilidade social e ambiental juntas. Ao posicionar as ações da Antena, o respondente a situou em nível intermediário, entre a responsabilidade social isolada e a que agrega a responsabilidade ambiental. Ele justificou que, além do Instituto agora haveria o Sistema de Gestão Ambiental e a certificação ISO 14001. Uma argumentação compartilhada por diversos gerentes, como mostram os fragmentos de entrevistas apresentados a seguir:

“A 'Antena' justifica a criação do Instituto, é a forma de exercer e fortalecer a prática da Responsabilidade Social na 'Antena', visando, especialmente, o desenvolvimento das comunidades onde a empresa está presente". (Gerente 17).

\section{“[...] [O Instituto] é uma capacitação importante da “Antena"”. (Diretor 1).}

“Quanto à responsabilidade social tem o Instituto 'Antena' do qual sou voluntária, que realiza vários projetos de cunho social. Embora seja um projeto ainda muito novo, com cerca de dois anos, acho um bom incentivo para aqueles que pretendem ajudar". (Gerente 9).

Observa-se que, no percurso semântico da responsabilidade social, o Instituto é sempre mencionado como fonte importante de reconhecimento da empresa. No fragmento 2, oriundo da entrevista com um 
diretor, destaca-se a seleção lexical do termo capacitação que remete ao tema implícito, subentendido, de que a Antena não era capaz de gerir, de equacionar o tema da responsabilidade social. Assim, buscou criar um Instituto, estrutura nova com gerências e poucos funcionários. Remete também ao tema explícito da aprendizagem, pois a organização está aprendendo a aproveitar a possibilidade de obter proveitos da responsabilidade social. Esse último tema surge como um implícito, subentendido, marcado pelos termos Pode denegrir a imagem, pode ser diferente e é um diferencial, evidenciados nos fragmentos a seguir:

"Com certeza, a responsabilidade ambiental é importante e essencial. Pode denegrir a imagem das empresas". (Gerente 14).

“Mostrar para a sociedade que ela pode ser diferente é um diferencial para a Antena". (Gerente 9).

A preocupação com o tema da responsabilidade social, para muitos dos gerentes entrevistados, está ligada à gestão da imagem da organização. Todos, sem exceção, garantem que se a empresa não explorar o tema, sua imagem na sociedade será facilmente denegrida. Nesse sentido, acreditam que é uma vantagem competitiva muito importante.

"Socialmente a empresa é superpreocupada, têm os projetos dos conselhos onde a empresa dá celulares para os conselhos tutelares das cidades envolvidas no projeto, o 'Tá na mesa'. Eu já trabalhei em várias outras empresas, como a Belgo [Mineira], e a que mais se preocupa com a questão de responsabilidade social é a

Antena. A questão social aqui é muito forte em relação às outras empresas”. (Gerente 5).

No fragmento anterior se evidencia o tema explícito da comparação entre as empresas no tocante à responsabilidade social, com a vitória da Antena. Deve-se lembrar que o avaliador é um de seus gerentes, mas para reforçar e legitimar essa vitória o gerente utiliza a estratégia discursiva de se apresentar no discurso como uma personagem que já esteve ligada a outras empresas e conhece os outros competidores, colocando-se, assim, em condições de fazer a avaliação. Outra estratégia utilizada foi nomear alguns projetos da Antena, para exemplificar sua superioridade, e silenciar sobre os projetos dos adversários.

De qualquer maneira fica evidente que a empresa incorpora demandas do governo e, a partir delas, elabora um projeto institucional para envolver seus empregados e a sociedade mineira. Para a gerência, a empresa, diferente de outras, está realmente envolvida com a responsabilidade social. Ela abraçou a causa e fez com que seus funcionários a acompanhassem, como se observa nos seguintes fragmentos.

“As empresas que têm preocupação social e ambiental criam diferencial junto ao seu ramo, ao público. É uma obrigação no tocante à sociedade e ao meio ambiente. No caso da Antena, a empresa se tocou destas necessidades e abraçou a causa. Essa postura vai ao encontro das necessidades dos funcionários de aderir aos programas. A responsabilidade social e ambiental é um diferencial criado e um reconhecimento". (Gerente 8).

“A responsabilidade social e ambiental é uma grande preocupação da Antena. É um ponto forte que claramente pode ser visto nos negócios da empresa. Sem dúvida nenhuma, a responsabilidade social e ambiental da Antena é uma grande vantagem competitiva. Muitas vezes, temos um preço mais alto e uma tecnologia menos avançada, como no caso da OI, mas a imagem da Antena está em alta, o que nos faz levar certa vantagem sobre as outras operadoras. Internamente, a responsabilidade social e ambiental é muito valorizada, principalmente através de grupos de voluntários, dos quais realmente vale a pena participar". (Gerente 13).

Novamente o discurso gerencial está tão alinhado com o da alta direção que chega a ser repetitivo, buscando indicar a existência do que Maimon (1992) identifica como posição responsável, e Fineman (1996) chamou de abertura a novas práticas. Esse último termo foi aqui escolhido para indicar o subconjunto composto pelo conjunto de temas apresentados. Entretanto, dentro do percurso semântico da responsabilidade social, esse subconjunto não está só, ele se coloca em oposição discursiva a outro, observado a partir da heterogeneidade no discurso dos técnicos, atores encarregados de operacionalizar as estratégias organizacionais. Desse grupo surgiram temas inseridos no subconjunto abertura e outros 
opostos a ele, indicando mais um subconjunto, identificado como o da dissimulação.

\section{O Percurso Semântico da Responsabilidade Social para os Técnicos}

Para os técnicos o tema da responsabilidade social é visto sob um olhar mais crítico que o da gerência. Além disso, diferentemente dos gerentes aparece uma diversidade de olhares sobre o tema, revelando um percurso semântico da responsabilidade social, em que se entrecruzam dois subconjuntos. O primeiro é o da descrença no tema da responsabilidade social da empresa. Afinal, ela é uma empresa que quer aumentar seu lucro; para isso usa várias estratégias; a responsabilidade social é uma delas e, segundo eles, a que deu certo. O desenvolvimento de projetos sociais com foco no ganho de abonos fiscais/abatimento no imposto de renda e retorno de imagem perante a sociedade surgiram como temas explícitos em discursos dos técnicos, como observado a seguir.

"Acredito que relacionado a esses projetos sociais está muito o interesse da empresa em se promover, em melhorar a sua imagem na sociedade. É uma questão de marketing”. (Técnico 3).

"Acho que não é uma preocupação assim com a sociedade; afinal de contas a Antena é uma empresa e que não está aqui para fazer caridade”. (Técnico 15).

“[...] é também motivar outras empresas a adotar programas de responsabilidade, passar a ter preocupação com o social, até por causa de abatimento no imposto de renda". (Técnico 9).

Nos fragmentos anteriores, destaca-se a ligação econômica da exploração do tema responsabilidade social por parte da empresa, ou seja, esse tema só está sendo mantido pela empresa para aumentar seus ganhos: na forma de incentivos fiscais; daí a Antena precisa também ensinar às outras empresas a fazerem isso (há aqui o implícito pressuposto de que as outras nada saberiam sobre esse caminho das pedras); no fortalecimento da imagem, pois a responsabilidade social é estrategicamente ligada a algum tema considerado nobre pelos clientes. Nesse sentido, evidencia-se mais uma vez uma conexão com a economia, pois os temas explorados pelos projetos de responsabilidade social devem ser considerados importantes pelos clientes, ou então não há fortalecimento da marca.

Como mencionado, esses temas compõem o subconjunto da dissimulação que, dentro do percurso semântico da responsabilidade social, está em oposição discursiva ao subconjunto da abertura que agrega temas defendidos pela alta direção, pela gerência, e também por diversos técnicos. Esse alinhamento de parte do grupo de técnicos ao subconjunto da abertura pode ser observado nos seguintes fragmentos discursivos.

"Responsabilidade social é o compromisso da empresa com a comunidade na qual está inserida no sentido de devolver para ela parte do seu lucro através de atividades relacionadas ao desenvolvimento social”. (Técnico 2).

"A empresa entende a necessidade de devolver parte do seu lucro para a sociedade; afinal é ela que a sustenta. É um processo de troca, recebe e dá de volta”. (Técnico 8).

O tema da responsabilidade social aqui se liga, de maneira explícita, com o do retorno para a sociedade de parte do lucro da empresa. Vários são os entendimentos sob esse prisma. Um tema implícito, subentendido, marcado pela recorrência dos termos lucro e devolver é o fato de que a empresa ganha muito. Ao perceber isso, ela devolve parte desse lucro por meio de projetos de cunho social. Deve-se observar que os termos compromisso da empresa e a empresa entende a necessidade, nos fragmentos 12 e 13, marcam o tema implícito, subentendido, de que a Antena tem responsabilidade social. Esse tema vai de encontro a outros temas destacados nos fragmentos 9, 10 e 11, quando no lugar da responsabilidade se tem o marketing e o abatimento de impostos. Esses dois posicionamentos caracterizam as oposições discursivas que marcam o percurso semântico da responsabilidade social na Antena. Dentro dessa configuração foi possível identificar diversos temas em oposição pertencentes a cada um dos dois subconjuntos destacados.

Para alguns técnicos a existência do Instituto representa responsabilidade social. Para outros, isso só 
vai ocorrer, quando eles tiverem poder de decisão sobre o tema, assumindo, por exemplo, maior participação no Instituto.

"Se os colaboradores tiverem poder de decisão em novas ações, quando tivermos participação no Instituto, podemos realmente demonstrar que a empresa se preocupa com a causa social". (Técnico 17).

De maneira semelhante o programa de voluntariado oferece temas tanto ao subconjunto da abertura quanto ao da dissimulação, como se observa a seguir.

"O programa de voluntariado [é importante]. Porque, enquanto cidadão e humano, eu me sinto na obrigação de contribuir". (Técnico 22).

"De dois em dois meses faço um trabalho que é ou uma visita a alguma creche, para trabalho de reforma, pintura, reparos na parte elétrica e hidráulica, ou arrecadação de alimentos, roupas [...]". (Técnico 4).

"Existe a equipe de voluntários da Antena, que vai em creches... Quando o programa começou, eu participava, agora não porque mudaram muito as coisas, pioraram, a gerência agora quase não participa mais, agora é mais só um grupo de funcionários". (Técnico 19).

"No início tinha uns 'consultores' para alavancar o programa (um grupo especializado, de fora da organização, que ajudava na formulação do programa). [...] Contudo, isso não funcionou. [...] Existe frustração, as pessoas (funcionários da Antena) 'quebram a cara', vêem que não é bem assim”. (Técnico 27).

Nos fragmentos 15 e 16 os termos contribuir e faço um trabalho remetem ao tema explícito de que os atores atuam no programa, e ao tema implícito, pressuposto, de que o programa funciona e tem sua importância. Já nos fragmentos 17 e 18 os termos piorou, a gerência agora quase não participa, só mais um grupo, não funcionou remetem aos temas explícitos de que o programa tem problemas quanto à participação dos funcionários e que esse problema tem relação com a atuação da gerência. Há ainda depoimentos que evidenciam o tema explícito do descontentamento com o fato de os empregados que trabalham voluntariamente não serem vistos diferentemente dos outros, ou seja, o tema voluntariado é associado ao tema implícito, pressuposto, de que participar de tais trabalhos estaria ligado a um possível reconhecimento da alta direção. Neste sentido, não seria então trabalho voluntário, mas uma forma de poder ganhar olhar diferenciado por parte da gerência.

No tocante à temática ambiental, essa configuração fragmentada entre os dois subconjuntos se reforça no discurso dos técnicos. Enquanto no discurso da alta direção e dos gerentes a temática ambiental se reforça e é associada à responsabilidade social, no grupo dos técnicos ela tanto é articulada dessa maneira, quanto para reforçar a idéia de dissimulação, como se observa nos fragmentos a seguir.

"A Antena, no contexto de grandes cidades, não tem muita relação tão grande com o ambiente no sentido de preservação da natureza. No contexto urbano tem mais a ver com o social. A Antena tem participação expressiva na área social, com o Instituto que mantém parcerias com entidades sociais, programa de voluntários, atividades culturais". (Técnico 1).

"[...] que gestão ambiental que nada, a Antena apenas preocupa-se em seguir a legislação municipal e procura estar sempre em conformidade com as regras da ANATEL, que faz constantemente fiscalizações". (Técnico 2).

"a Antena é importante por sua preocupação com o meio ambiente e com a comunidade". (Técnico 2).

"Nós temos que dar o exemplo e participar das ações da empresa em nível da responsabilidade social e em nível do meio ambiente...". (Técnico 24).

Os dois primeiros fragmentos oferecem ao subconjunto da dissimulação temas explícitos, como a falta de preocupação com a natureza e a limitação com preocupações legais. Já os dois últimos reforçam no subconjunto da abertura temas explícitos como a preocupação da Antena com a responsabilidade social e com a temática ambiental, e o tema implícito, subentendido, da motivação para que todos participem dessa iniciativa. 
Essa ambigüidade da convivência entre discursos divergentes indica movimentações. Como explicam Knights e Morgan (1991), são grupos que buscam alinhar seus discursos com os dos privilegiados, no caso os da alta direção, compondo o subconjunto da abertura. Opondo-se a eles, outros atores optam pelo caminho alternativo da bricolagem (Certeau, 1994), ou seja, por meio dela usam elementos de um discurso contra ele próprio, como os técnicos que falam do voluntariado para destacar a falta de participação dos gerentes; assim, surge o subconjunto da dissimulação. Da oposição entre abertura e dissimulação emerge a resposta para o questionamento de como se configuram os discursos sobre a responsabilidade social na Antena e sua incorporação da temática ambiental. Há um imbricamento entre as temáticas, elas surgem comumente em conjunto nos discursos dos atores organizacionais. Um grupo predominante, com vários membros em posições privilegiadas, incorpora esses temas em seus discursos para evidenciar que a Antena está mudando, construindo uma abertura para assumir a sua responsabilidade social. Outro grupo, composto por parte dos técnicos, revela em seus discursos que, por trás dessa abertura, há dissimulação, em torno de interesses menos relacionados com responsabilidade e mais com a competitividade.

Dessa configuração discursiva é possível entender o que Holmer-Nadesan (1996) chama de visão de mundo predominante na organização, alcançável por meio dos discursos de seus atores. No caso, a preocupação com a responsabilidade social, já incorporando a temática ambiental, norteia as relações entre a organização e a sociedade. A preocupação está em algumas de suas ações, na fala da alta direção, dos gerentes e de boa parte dos técnicos. Entretanto eles silenciam sobre os limites dessa responsabilidade, um silêncio preenchido por parte dos técnicos que destacam a preocupação organizacional constante com o retorno em termos econômicos, com a imagem e com a legislação. Portanto, defende-se que aquela responsabilidade é um fato. A abertura existe, mas a dissimulação se concretiza no momento em que essa abertura ameaça objetivos organizacionais específicos. Ela é caminho para alcançá-los, não tem fim em si mesmo. Um entendimento que vai ao encontro das contribuições de Schommer e Fischer (1999), que destacaram o fato de a responsabilidade social no Brasil estar voltada para os retornos que as organizações podem obter.

\section{CONSIDERAÇÕES FINAIS}

Como proposto na argumentação teórica, o estudo de caso apresentado evidenciou um cotidiano organizacional, em que os discursos que envolvem responsabilidade social se configuram de maneira fragmentada. As faces econômica, legal, ética e filantrópica da responsabilidade social (Carroll, 1998) revelaram suas tensões e ambigüidades que marcaram as oposições discursivas na organização investigada. Isso também corrobora o entendimento que o estudo dessas configurações discursivas permite evidenciar tais ambigüidades. Elas são utilizadas pelos atores, ao articularem suas estratégias de persuasão, no caso tendo o pesquisador como o destinatário.

Como foi observado, na Antena os atores organizacionais manifestaram, de maneira recorrente e conjunta, temas ligados à responsabilidade social e à temática ambiental, em alguns casos até para manifestar a inexistência de um ou de ambos na organização. Os temas permeiam a organização, estando presente nos discursos de seus atores. Essas evidências vão ao encontro do entendimento de Schommer, Fischer (1999) e Melo (1999) sobre a disseminação dessas temáticas no cotidiano organizacional brasileiro.

No tocante às ações práticas, o discurso que afirma existir abertura efetiva para esses temas na organização destaca ações como a criação do SGA, a certificação ISO 14001, a criação do Instituto Antena, e as atividades realizadas por ele e seus parceiros. Segundo os próprios locutores, por ser empresa mineira e de atuação na mesma região, a Antena procura desenvolver a confiança e a tradição em seus clientes e, para tanto, utiliza as ações sociais para frisar essas qualidades. Nesse sentido, a organização contribui na gestão de projetos locais e, ao mesmo tempo, utiliza-se deles como fonte de estratégia social, política e econômica para alcance de seu sucesso. A obtenção de benefícios mercadológicos e institucionais por meio desse discurso é algo consensual na Antena, como Zouain 
(2001) já destacava em relação a outras organizações. Entretanto esse consenso não permanece, quando se observam os fins e os limites das ações. Aqui, a organização se divide em torno de dois subconjuntos do percurso semântico da responsabilidade social.

Um primeiro grupo, predominante, formado pela alta direção, gerentes e parte dos técnicos, se volta para o subconjunto chamado de abertura e tende a alinhar a organização com o que Fineman (1996) chama de abertura para novas estratégias no tocante à gestão ambiental. Nesse caso, os locutores associam a responsabilidade social à temática ambiental e buscam estratégias de persuasão discursivas para legitimar essa posição. Entretanto foi observado que eles silenciam sobre os limites e os fins dessa responsabilidade.

O segundo grupo utiliza temas e personagens semelhantes ao do grupo predominante, o Instituto, o SGA, o voluntariado. Porém, por meio da bricolagem (Certeau, 1994), os articula de maneira a demarcar um espaço no silenciamento do grupo anterior e constrói o subconjunto, aqui chamado de dissimulação, subconjunto que alinha a organização ao que Fineman (1996) identificou como dissimulação, na qual as organizações fingem a abertura, mas não mudam ações e planos concretos e mesmo assim buscam os benefícios da abertura.

Esse subconjunto da dissimulação não afastou a organização da responsabilidade social e da temática ambiental; pelo contrário, as faces da responsabilidade social manifestadas indicam que os temas efetivamente permeiam a organização. $\mathrm{O}$ que se revelou foi uma fragmentação no tocante às ambigüidades de buscar ocultar limites, que são concretos, e se direcionam para os interesses econômicos, uma face da responsabilidade social reconhecida por Carroll (1998) e por Schommer e Fischer (1999).

Nesse contexto, o que prejudica ou beneficia a sociedade só tem importância, a partir da capacidade de determinadas instituições e grupo de atores as perceberem. Dentro das ambigüidades e fragmentações evidenciadas, observou-se um direcionamento das preocupações organizacionais para as percepções desses atores. Logo, um caminho de médio prazo para aproveitar essa tendência seria articulá-los em torno de interesses da sociedade. Dessa maneira, podem surgir retornos sociais que se aproximem de uma suposta conscientização da alta direção organizacional, enquanto se espera que essa conscientização realmente se concretize.

Artigo recebido em 14.09.2006. Aprovado em 14.02.2007.

\section{AGRADECIMENTOS}

Agradecemos Pablo Alexandre Gobira de Souza-Ricardo pela revisão técnica e gramatical deste artigo.

\section{NOTAS}

\footnotetext{
${ }^{1}$ Por não se desejar identificar os atores envolvidos na pesquisa, decidiu-se omitir o nome da empresa de telefonia. O artigo trará o nome fictício Antena, quando tratar da empresa.

${ }^{2}$ A ISO 14001 trata de normas internacionais de gestão ambiental. Ver Bittencourt, Zimmer e Foelkel (1997).

${ }^{3}$ No Brasil, esse mercado ainda é frágil, pois nem se resolveu a questão básica da segurança alimentar (Layrargues, P. P. (2000). Sistemas de gerenciamento ambiental, tecnologia limpa e consumidor verde: a delicada relação empresa-meio ambiente no ecocapitalismo. Revista de Administração de Empresas, 40(2), 80-88.).

${ }^{4}$ Antena (1993). Relatório anual de gestão da empresa Antena (Vol. 1, Num. 1 ). Rio de Janeiro: Editora Antena.

${ }^{5}$ Antena (2004). Relatório de ações ambientais da empresa Antena (Vol. 1, Num. 1 ). Rio de Janeiro: Editora Antena.
} 
${ }^{6}$ Antena (2004).

\section{REFERÊNCIAS BIBLIOGRÁFICAS}

Alvesson, M. (1990). Organization: from substance to image. Organization Studies, 11(3), 373-394.

Ashley, P. A., Coutinho, R. B. G., \& Tomei, P. A. (2000, setembro). Responsabilidade social corporativa e cidadania empresarial: uma análise conceitual comparativa. Anais do Encontro Nacional da Associação Nacional de Pós-Graduação e Pesquisa em Administração, Florianópolis, SC, Brasil, 24.

Bittencourt, C. C., Zimmer, C., \& Foelkel, C. (1997, setembro). Percepção pelo público interno acerca dos sistemas de gestão ISO 9002 e ISO 14001 na Riocell. Anais do Encontro Nacional da Associação Nacional de Pós-Graduação e Pesquisa em Administração, Rio das Pedras, RJ, Brasil, 21.

Bonin, A. A. (1993). Acteurs e consommateurs: valeurs et strategies. In R. H. Green \& R. R. Santos (Orgs.). Brésil: un système agro-alimentaire en transition. Paris: IHEAL.

Carroll, A. B. (1998). The four faces of corporate citizenship. Business and society review, 100(101), 1-7.

Carvalho, L. C. M. (1991). Territorialidade em luta: uma análise dos discursos ecológicos. IF, Série Registros, 9, 1-56.

Certeau, M. (1994). A invenção do cotidiano. Petrópolis: Vozes.

Donaire, D. (1994). Considerações sobre a influência da variável ambiental na empresa. Revista de Administração de Empresa, 34(2), 68-78.

Faria, A. A. M. (2001). Interdiscurso e intradiscurso: da teoria à metodologia. In E. A. de M. Mendes, P. M. Oliveira, \& V. Benn-Ibler (Orgs.). O novo milênio: interfaces lingüísticas e literárias (pp. 31-37). Belo Horizonte: FALE/UFMG.

Fernandes, F. (1973). Fundamentos empíricos da explicação sociológica. São Paulo: T. A. Queiroz/Edusp.

Fineman, S. (1996). Emotional subtexts in corporate greening. Organization Studies, 17(3), 479-500.

Fiorin, J. L. (1989). Elementos de análise do discurso. São Paulo: Contexto.

Fiorin, J. L. (2003). Linguagem e ideologia (7a ed.). São Paulo: Ática.

Gutberlet, J. (1996). Produção industrial e política ambiental. São Paulo: Fundação KonradAdenauer-Stiftung.

Holmer-Nadesan, M. (1996). Organizational identify and space of action. Organization Studies, 17(1), 49-81.

Hooghiemstra, R. (2000). Corporate communication and impression management - new perspectives why companies engage in corporative social reporting. Journal of Business Ethics, 27(1-2), 5568 .

Kitamura, P. C. (1994). A agricultura e o desenvolvimento sustentável. Agricultura Sustentável, 1(1), 2732.

Knights, D., \& Morgan, G. (1991). Corporate strategy, organizations and subjetivity: a critique. 
Organisation Studies, 12(2), 251-273.

Maimon, D. (1992). Empresa e meio ambiente. Tempo e Presença, (261), 46-48.

Martinelli, A. C. (1997). Empresa cidadã. In E. Ioschpe (Org.). $3^{\circ}$ setor: desenvolvimento social sustentado (pp. 81-88). Rio de Janeiro: Paz e Terra.

Melo, F. P. Neto (1999). Responsabilidade social e cidadania empresarial: a administração do terceiro setor. Rio de Janeiro: Qualitymark.

Nascimento, L. F. (Coord.). (1997). Avaliação do perfil ambiental das empresas do setor metalmecânico no Rio Grande do Sul. Porto Alegre: NITEC.

Poirier, J., Clapier-Valladon, S., \& Raubaut, P. (1983). Les récits de vie: théorie et pratique. Paris: Puf.

Reed, M. (1996). Organizational theorizing: a historically contested terrain. In S. R. Clegg, C. Hardy \& W. Nord (Eds.). Handbook of Organization Studies (pp. 31-56). London: Sage.

Reed, M. (1998). Organizational analysis as discourse analysis: a critique. In D. Grant, T. Keenoy \& E. Oswick (Eds.). Discourse and organization (pp. 193-213) London: Sage.

Schommer, P. C., \& Fischer, T. (1999). Cidadania empresarial no Brasil: os dilemas conceituais e a ação de três organizações baianas. Organizações \& Sociedade, 6(15), 99-118.

Shrivastava, P. (1994). Castrated environment: greening organizational studies. Organization Studies, 15(5), 705-726.

Thiollent, M. J. M. (1987). Crítica metodológica, investigação social e enquete operária. São Paulo: Polis.

Viola, E. (1996). A multidimensionalidade da globalização, as novas forças sociais transnacionais e seu impacto na política ambiental do Brasil, 1989-1995. In L. C. Ferreira \& E. Viola (Orgs). Incertezas de sustentabilidade na globalização. Campinas: Editora Unicamp.

Weick, K. E. (1991). The vulnerable system: an analysis of the Tenerife air disaster. In P. J. Frost, L. F. Moore, M. R. Louis, C. C. Lundberg, \& J. Martin (Eds.). Refraiming organizational culture. (pp. 117-130). London: Sage.

Zouain, D. M. (2002, setembro). Desenvolvimento da dimensão comunitária da responsabilidade social das organizações: um estudo de caso sobre a LIGHT e suas contribuições para o desenvolvimento humano sustentável, a inclusão social e a cidadania. Anais do Encontro Nacional da Associação Nacional de Pós-Graduação e Pesquisa em Administração, Salvador, BA, Brasil, 26. 